\title{
THE REPRESENTATION OF WOMEN'S CEO IMAGE IN ONLINE MEDIA
}

\author{
Diah Kristina $^{1}$; Melsiana Shera Rita Ramadona ${ }^{2}$ \\ 1,2,English Department, Sebelas Maret University \\ Jl. Ir. Sutami No. 36-A, Kentingan, Surakarta 57126, Indonesia \\ 1'diahkristina@staff.uns.ac.id; ${ }^{2}$ melsianashera@gmail.com
}

Received: $25^{\text {th }}$ July 2019/Revised: $02^{\text {nd }}$ August 2019/Accepted: $14^{\text {th }}$ August 2019

How to Cite: Kristina, D., \& Ramadona, M. S. R. (2019). The representation of women's CEO image in online media. Lingua Cultura, 13(3), 201-207. https://doi.org/10.21512/lc.v13i3.5785

\begin{abstract}
The research focused on the representation of women in the news about the absence of women in Uber's CEO candidates from the perspective of feminist stylistics by Sara Mills. Five news texts from five different websites published during August 2017 were analyzed; they were Washington Post, Daily Mail, Inverse, Gizmodo, and Fortune. The method used was a qualitative research method with the approach of critical discourse analysis of Sara Mills. By applying three levels of analysis which was analysis at the level of the word, phrase/sentence, and discourse, this research aimed to analyze how women were represented linguistically in the online news of Uber's CEO candidates and to discover the reason why women were represented in the way they were. The findings reveal that women remain underrepresented in news media. It is proved by the dominance of women as the object in the stories. Moreover, women are represented as 'glass cliff position', minority, and a way to recreate the good image in the company. The gender stereotypes, the background story of Uber, the male-dominated industries, and the prevalent condition become the reasons why women represented that way.
\end{abstract}

Keywords: women representation, women image, online media, critical discourse analysis

\section{INTRODUCTION}

The representation of women in news discourse has been a discussion over the last two decades. However, the researchers have found that women remain underrepresented in news media (York in Geertsema-Sligh, 2019). According to Mills (1988), women are often referred to in a different way from men in newspaper reports. Men are usually referred by their occupations or appearance, while women are often referred by their relationship with others, such as 'mother of two' and 'wife'. Above all, Mills has found that woman is socially constructed as a marginal position in the text always in the wrong position (Kristina, 2019). In conclusion, those researches show that in the news discourse, the social roles still belong to the male domain.

The language of news media has been explored by linguists in different approaches; one of them is the Critical Discourse Analysis (henceforth CDA) approach. According to Van Dijk (2015), CDA is discourse analytical research that primarily studies the way social-power abuse and inequality are enacted, reproduced, legitimated, and resisted by text and talk in the social and political context. Furthermore, CDA is critical research that concerns with social problems and the understanding of human rights, social inequality, power abuse in domains such as racism, sexism, classism, et cetera (Van Dijk, Wodak, and Meyer, 2009 in Ramanathan, 2015).
Research on media representation of women in newspapers has been carried out by many researchers. Several studies have found that women remain significantly underrepresented in written news media (Aznar, RodríguezWangüemert, \& Espinosa, 2017; Shor et al., 2015). The research from Aznar, Rodríguez-Wangüemert, and Espinosa (2017) has also suggested that the representation of women and men is informed by gender stereotypes that attribute the power and authority to men. Besides, Len-Rios et al. (2005) have found that the newspapers sustain gender stereotypes by showing women in more 'feminine' news sections and men in more 'masculine' sections.

Similarly, Jia et al. (2016) have suggested that the news media are still very much male-dominated. The media still portrays women in the roles of fashion and entertainer, despite their advances in professional occupations and political offices, while men are more associated with business and politics. The recent research by Ryan (2013) has found that media bias may increase as women move up to more executive offices, but only slightly. The mention of appearance and marital status or family decrease as the women move to more executive positions.

However, most of these researches only reach the level of word and phrases without the consideration of the discourse analysis. Besides, they still use the gender difference without the consideration of feminist perspective. There is one research from Suryaningrum, 
Suwandi, \& Waluyo (2019), which analyzes about women discrimination using feminism approach, but they analyzed different media, which are novels. Research from Darta \& Kristina (2018) is also using the feminist approach to analyze women representation, but they analyze women in the movie. Therefore, based on those research gap, this research will analyze the women representation in the newspapers from the perspective of feminist stylistics by Sara Mills.

The feminist stylistics is the type of analysis that puts women as the focus of the analysis. The stylistics feminist, which is proposed by Mills (1998) combines literary and linguistics theories by drawing on the theory of feminist stylistics to interpret and to analyze its textual language to answer the questions related to the representation of women and feminism.

Mills (1988) has divided her feminist stylistics analysis into three levels. The three levels of analysis are the level of the word, level of phrase/sentence, and level of discourse. Level of word focuses on general and theoretical aspects of sexism. This stage examines the usage of such as the sex-specific pronoun use, the generic terms, address terms, and the negative descriptions of females in a variety of texts. While the level of phrase/sentence focuses on the way that phrases and sentences make sense in their relation to the context and background knowledge. This stage examines the usage of such as presupposition and inference, metaphor, and transitivity choices. Lastly, the level of discourse relates to the micro context of the effect of words across sentences and the macro context of larger social patterns. This stage focuses on the larger-scale structure at the level of discourse, such as character/roles, fragmentation, focalization, and schemata.

By adopting the feminist stylistics analysis, this research will examine the representation of women in the Uber's CEO candidates-related news. Uber is a transportation network company, which allows the passengers to order a taxi by using the smartphone application. The company has a bad reputation for toxic masculinity within the workplace since former Uber engineer, Susan Fowler, wrote on her blog on February 2017 that the company failed to act on sexual harassment and gender discrimination complaints. For this reason, Chief Executive Officer (CEO), Travis Kalanick has resigned back in June. Regarding this matter, the media writes that Uber will pick a female CEO as the new CEO to change its image and build a new and improved brand. Several female executives have been approached to the job, but no one interested in taking the offer.

The objectives of this research are to see how women are represented linguistically in newspapers, especially female workers, and to analyze the reason why women are represented in the way they are. This research will analyze five websites which publish news related to the absence of women in the Uber's CEO candidates; they are Washington Post, Daily Mail, Inverse, Gizmodo, and Fortune. By analyzing women representation in media, especially news, it will show how the language used in represent man and women in media from the point of view of feminist stylistics. Afterward, the result of this research may inform the readers to be aware of reading news text related to the stereotypes of women in newspapers.

Representation in media is selected because media is one of the most powerful tools to communicate. It has the power to influence people on how to perceive women and men. Moreover, many people use media platforms to get the latest information. Research from Newman et al. (2017) has found that more than half of Americans (51\%) now say they use social media for news. Besides, the content of media is important for women because "the content of the media distorts women's status in the social world" (Tuchman in Ali \& Batool, 2015). Providing the importance and effect that media has, this research tries to analyze how women are represented linguistically in news media.

\section{METHODS}

This research uses the descriptive and qualitative method by describing the characteristics of the phenomenon being discussed and constructs it holistically to find the representation of women in the news. The data are taken from five different news texts in five different websites; they are Washington Post, Daily Mail, Inverse, Gizmodo, and Fortune. The words and sentences are those related to represent women. The previous research relating to women representation is used to deepen the discussion as well.

The news texts are analyzed using the feminist stylistics approach by Sara Mills that is one of CDA approaches. The analysis is started from the classifying each data based on the three levels analysis, which are the level of the word, phrase/sentence, and discourse. The next step is analyzing and interpreting the data to answer the problem statements. The data are given the code to make the analysis easier. The data coding is based on the name of the websites, the level of analysis, the classification of each analysis, the category of gender, and the number of data, for example (WP/LoW/LD/F/1). The coding means that the first data is on the Washington Post website. It includes the analysis at the level of the word, and it is classified as Linguistic Determination. Moreover, the data referring to female and belongs to data number 1 .

\section{RESULTS AND DISCUSSIONS}

The results and discussion of this research will be presented according to the three levels analysis category; they are analysis at the level of the word, level of phrase/ sentence, and level of discourse. Table 1 shows the analysis results at the level of the word.

Table 1 The Analysis Results at the Level of Word

\begin{tabular}{llcc}
\hline Types of Analysis & \multicolumn{1}{c}{ Word } & Frequency & \% \\
\hline LD (refers to & Chair & 1 & 3 \\
women) & Chief & 2 & 6 \\
& Executive & 1 & 3 \\
LD (refers to men) & Chairman & 6 & 17 \\
GFL & Female & 20 & 57 \\
& Male & 5 & 14 \\
\hline \multicolumn{2}{c}{ Total } & 35 & 100 \\
\hline
\end{tabular}

Based on the analysis at the level of the word in Table 1, two types of the analysis found in the news texts are the linguistic determinism and the gender-free language. The linguistic determinism deals with how the writers use the labels and terms in representing women and men. It is 
important to analyze the labels and terms that are used by the writers because some terms have sexist meanings existing in this society. In the news, the writers use the gender-neutral term when reporting a female; 'chair'. On the other hand, they use 'chairman' when reporting about a male.

According to Cameron (in Darweesh \& Abdullah, 2016), "Sexism does not reside in certain words and phrases, but it resides in the beliefs that see women as being inferior to men." Therefore, the use of 'chairman' is considered has a sexist meaning since it can be interpreted as the higher status of the male speaker. Furthermore, there is no equal term that is used to refer a female, in this case, the pair of word 'chairman', which is 'chairwoman'.

This discovery is consistent with the finding from previous research by Mills (1988) that has discussed the use of masculine language by the writers. The use of 'chairman' for men and 'chair' for women dominates the news text. This usage implies the higher status of male speakers. However, in the news, the writers do not mention the marital status of the women at all. Therefore, it is different from what Mills (1988) has found that women are often referred to in terms of their sexuality and relationships with others. It is because women have different occupations. In Mills's analysis, the women are mainly working as housewives, while in this research, the women are work as executives. As Ryan (2013) has found that the mention of marital status and or family decreases as the women move to more executive positions. In this research, the mention of marital status and or family is zero because the women are in executive positions.

The next is gender-free language, where the address terms that are used is genuinely generic unless a genderspecific term is necessary (Mills, 1988). These can be taken that the usage of 'female' and 'male' in this datum is done equally because the 'male' that is used to have an equal measure with 'female'. Consequently, in this stage, the writers do not use a sexist language when describing women. As the 'female' that is used here really meant a woman, there is no presupposition behind it. Furthermore, it is used to mark the gender of executives. Eventually, from the analysis at the level of the phrase, four types of the analysis found in the news texts are linguistic determinism, presupposition and inference, metaphor, and transitivity choices. Table 2 shows the analysis results on linguistic determinism.

Table 2 The Analysis Results on Linguistic Determinism

\begin{tabular}{clcc}
\hline No & Phrase (refers to women) & Frequency & $\mathbf{\%}$ \\
\hline 1. & Chief Executive & 4 & 20 \\
2. & Chief Executive Officer & 10 & 50 \\
3. & Chief Operating Officer & 4 & 20 \\
4. & Senior Vice President & 2 & 10 \\
\hline \multicolumn{2}{c}{ Total } & 20 & 100 \\
\hline
\end{tabular}

The examples of linguistic determinism are also found in the level of phrase. As shown in Table 2, the writers use gender-neutral phrases 'chief executive', 'chief executive officer', 'chief operating officer', and 'senior vice president' to report a female. As described previously in the level of word, the use of gender-neutral terms when describing woman and the label 'chairman' when describing men show how the writer perceives the idea of men and women in the workplace, where men have a higher-status position, even when they have the same position as a chair in the company.

Subsequently, presuppositions are often found in sentences that can lead the readers to have certain assumptions, while inferences are implied through words that lead the readers to make assumptions (Mills, 1988). Table 3 shows the analysis results on presupposition and inference.

Table 3 The Analysis Results on Presupposition and Inference

\begin{tabular}{clcc}
\hline No & Presupposition and inference & Frequency & \% \\
\hline 1. & Related to the headline & 5 & 25 \\
2. $\begin{array}{l}\text { Related to women as CEO } \\
\text { candidates }\end{array}$ & 7 & 35 \\
3. $\begin{array}{l}\text { Related to women get cleanup } \\
\text { jobs }\end{array}$ & 3 & 15 \\
3. $\begin{array}{l}\text { Related to women face serious } \\
\text { challenges }\end{array}$ & 1 & 5 \\
4. $\begin{array}{l}\text { Related to Uber's toxic work } \\
\text { culture for women }\end{array}$ & 3 & 15 \\
5. $\quad$ Related to gender imbalance & 1 & 5 \\
\hline \multicolumn{1}{c}{ Total } & 20 & 100 \\
\hline
\end{tabular}

As can be seen in Table 3, the presuppositions and inferences in the news texts are divided into six categories. The first one is the presuppositions related to the headline. All the news texts have headlines that presuppose that Uber's new CEO is going to be a male, not female. The examples of the headline are:

"Uber's Search for a Female CEO has been Narrowed Down to Three Men"

"Uber's Hunt for a Female CEO has been Narrowed Down to a List of Three Men in the Wake of the Company's Sexual Harassment Allegations"

"Uber Can't Find a Female CEO, so the Top Contenders are Three Men"

"Uber Can't Find a Woman to be a CEO, so has Bravely Narrowed Their Search Down to Three Dudes"

“Uber has Three CEO Candidates Left—and They're All Men"

These headlines imply that Uber's new CEOs are supposed to be female, but Uber cannot find one. There will be many reasons why Uber cannot find a woman to be a $\mathrm{CEO}$, whether because there is no woman that is capable of leading Uber or anything else. Those presuppositions could lead to negative assumptions towards women. When actually, it is because the female candidates turn down the offer, as the writer explains in the body. The next presuppositions are related to women as CEO candidates. The examples of the presuppositions are:

“A company trying to recover from allegations of rampant sexism might reasonably think that hiring 
a female chief executive would help it restore credibility with customers and - perhaps more importantly — with potential employees in a tight marketplace for talent."

“Uber's plan to replace CEO Travis Kalanick with a woman in an attempt to combat claims of a toxic and misogynistic office culture have hit a wall."

"As Uber tries to change its image and build a new and improved brand, a natural move is to include women in executive roles within the company. There's just one problem: apparently none of them want the gig."

Those presuppositions make earlier suggest very strongly the impression that the company only needs a female CEO to help to restore their declining credibility. Furthermore, the company has many controversies about their toxic workplace, where a former engineer, Susan Fowler, has said that she was sexually harassed by her supervisor and the human resources department ignored the claims. Besides that, Uber also has 47 cases related to sexual harassment. As Mills (1988) has stated that presupposition helps to know the intended meaning of the speaker, the sentences imply that Uber purposely searches for a female CEO to help them restore their bad credibility, not because of the capability of the female CEO candidates.

The next presupposition is about women gets cleanup jobs. The examples of the presupposition are:

"As much as I would love to see more women chief executives, too often women get the cleanup jobs, and I'd prefer to not always see women get the cleanup jobs."

"But there are even more reasons for a woman to shy away from Uber's top spot. There's no telling just how deep misogyny runs at the company, potentially weakening her authority. And as the Post points out, women are often elevated to top jobs in times of crisis, only to be castigated when they fail to fix problems caused by their predecessors."

"A woman at the helm could deflect such criticisms of the company for a time, but she would eventually have to shoulder responsibility for its problems."

The next presupposition is about women who face serious challenges. The sentence, "She added that women in CEO and COO positions face 'serious challenges' that men in those roles do not," makes the assumption that women go through a difficult task when being a CEO and COO. Conversely, men do not have it as hard as women. This because there are so few women in the workplace; therefore, they need to prove that they are as good as men.

The next presuppositions are about Uber's toxic work culture for women, the examples are:

"Uber's toxic work culture came under fire in February, following engineer Susan Fowler's blog post about her time at the company. In the post, she details sexual harassment, discrimination, and a very apathetic HR department."

"Uber, the ride-hailing giant which became mired in internal fighting and leadership intrigue after the resignation of its former CEO Travis Kalanick, appears to have scared off every female candidate willing to entertain the notion of replacing him."

"But there are even more reasons for a woman to shy away from Uber's top spot. There's no telling just how deep misogyny runs at the company, potentially weakening her authority. And as the Post points out, women are often elevated to top jobs in times of crisis, only to be castigated when they fail to fix problems caused by their predecessors."

Those sentences imply that Uber work culture is unacceptable, especially for women. Susan Fowler makes the blog post because the HR department ignores her report about sexism and sexual harassment that she has experienced in the company. It shows that the Uber company does not give fair treatment to their female workers. Moreover, the word 'misogyny' used by the writer shows strong prejudice against women that the Uber company has with women. Considering those, the work culture at Uber is certainly toxic and unpleasant for women.

The last examples of presuppositions are related to gender imbalance. The sentence, "Trying to hire a female CEO could even be interpreted as a cynical bit of highlevel tokenism from a company now nearly synonymous with the worst of Silicon Valley 'tech bro' culture," implies Uber is as worst as Silicon Valley when it comes to the way of treating women. The words, "silicon valley 'tech bro' culture" refer to the gender imbalance and the predominance of the technology industry, especially computing. They are infamous with sexism and sexual harassment in the office.

Afterward, there are examples of metaphor found in the news texts. Metaphor is a word or phrase which uses an analogy to suggest similarity in one respect between two things (Mills, 1988). In some cases, the metaphor may influence the readers to think about certain scenarios in, particularly stereotyped ways. There are two metaphors found in the texts, 'glass cliff' and 'adult in the room'. The first one is 'glass cliff' that refers to the tendency of a company to put women in the leadership position during times of crisis when the chance of failure is highest (Ryan \& Haslam in Bruckmuller et al., 2014). Ryan and Haslam (in Bruckmuller et al., 2014) have stated that when an organization is in crisis, this is likely to be seen as an indication that the current approach is not working and that a change from the current (most likely male) model of leadership is needed. This condition happens in the Uber company; they are in crisis and need a new CEO. It is mainly because they have several issues on women in the company to cope with, namely sexism and sexual assault. Therefore, by changing their CEO with a woman, they hope it can fix the issues and change their bad image.

The next metaphor 'adult in the room', is used to describe Sandberg, the CFO of Facebook, in a positive way. The writers use him as an example of a successful executive who can do his job very well. However, the writers also give an example of a contrasting case when Marissa Meyer fails to do her job to turn a company (in this case, Yahoo) around and she gets negative attention because of that. Therefore, the phrase 'adult in the room' has a sexist message underlined it because it is used to express a man who makes rational decisions for his company. On the other hand, the woman is represented as a bad example of a person who fails at saving the company. These can be seen that the writers imply the message that men are more capable than women in doing a job. This shows the stereotype that leadership role has 
always been predominantly male. In contrast, women have stereotypes that they do not fit the leadership roles, unless for glass cliff positions.

The last category from the level of phrase/sentence is transitivity choices. Transitivity is concerned with how the actions are represented, who is acting as the subject and who is acting as the object. In order to analyze the transitivity choices in the news texts, the actor in each process is extracted, with the lexical realization of each process associated with them (Mills, 1988). The results of the transitivity analysis are shown in Table 4.

Table 4 The Analysis Results on Transitivity Analysis

\begin{tabular}{ccccccc}
\hline $\begin{array}{c}\text { Char- } \\
\text { acter }\end{array}$ & Position & \multicolumn{3}{c}{ Transitivity process } & $\begin{array}{c}\text { Fre- } \\
\text { quency }\end{array}$ & $\%$ \\
\cline { 3 - 6 } & $\begin{array}{c}\text { Mate- } \\
\text { rial } \\
\text { action } \\
\text { inten- } \\
\text { tion }\end{array}$ & $\begin{array}{c}\text { Mental } \\
\text { inter- } \\
\text { nalized } \\
\text { pro- } \\
\text { cess }\end{array}$ & $\begin{array}{c}\text { Rela- } \\
\text { tional } \\
\text { pro- } \\
\text { cess }\end{array}$ & & \\
\hline \multirow{2}{*}{ Women } & Subject & 10 & 9 & 9 & 28 & 37,33 \\
& Object & 8 & 19 & 20 & 47 & 62,67 \\
\hline \multicolumn{2}{c}{ Total } & 18 & 28 & 29 & 75 & 100 \\
\hline
\end{tabular}

The result shows that across all websites, expect Washington Post, the portrayal of women as object dominated in the news. From the transitivity analysis at the level of phrase/sentence, it shows that writers are dominated in making women as the object of the stories. For examples:

"A company trying to recover from allegations of rampant sexism might reasonably think that hiring a female chief executive would help it restore credibility with customers and - perhaps more importantly — with potential employees in a tight marketplace for talent." = mental internalized process

"As Uber tries to change its image and build a new and improved brand, a natural move is to include women in executive roles within the company." = material action intention

"Former Yahoo CEO Marissa Meyer, whose failure to turn around the struggling portal has made her a target of harsh criticism, is a sterling example." = relational process

Those are the processes that have women as the object in the news. The position of the object means the object is a matter or a person who act as a receiver. Besides, the object is to whom its existence is described through the subject's perspective (Mills, 1988). In this present research, the writers mainly act as the subject of the story. It is because although the news is talking about the absence of women from Uber's CEO candidates, women are not the one who describe their own side. The stories are described through the writers' point of view. This discovery is relevant with research from Jia et al. (2016) that has said women are more likely to be represented visually than they are mentioned as a news actor or source.

On the other hand, the analysis of characters in the level of discourse shows the characters of women described based on a phenomenon that happened in the workplace.
The first one is the 'glass cliff' phenomenon that already discussed in metaphor. It has been seen here that it becomes a stereotype that woman can be exploited if something wrong happens in the company. Even the writers think it is common and they give a reference from experts about the phenomenon. Moreover, the phrase 'cleanup jobs' also has the same messages with 'glass cliff' that women are often exploited to solve the problem of a company in times of crisis. Furthermore, this sentence comes from a woman, Elizabeth Ames, a senior vice president at the Anita Borg Institute for Women and Technology. This shows that in western countries, the gender stereotypes in the workplace still exist.

The next is about women as a minority in the workplace. As already discussed, women tend to be judged harsher than men if they are failed at their jobs. This implies that in the workplace, women still get unfair treatment and discrimination. The writers also give the example of the women CEOs that get negative attention when they are failed at their jobs, such as Marissa Meyer, Ellen Pao, Sheri McCoy, and Irene Rosenfeld. This discovery is relevant to Len-Rios et al. (2005) that have found newspapers studied here reflect the masculine cultural hegemony that prevails in U.S. culture.

The next is that women are described as a way to recreate a good image in the company. As has been discussed in presupposition and inference, Uber only wants a female CEO to build a new and improved brand, since they have many controversies regarding how bad their workplace culture for women. Above all, the sentences are cited from experts, which shows that it is a common way in U.S. businesses to approach women for a leadership position to regain a good image when controversies about sexual harassment and toxic macho culture in the offices take place.

Lastly, there is a new finding used by Washington Post and Daily Mail which shows that the writers use sources from studies and experts. For examples:

\begin{abstract}
"Workplace experts pointed to a phenomenon known to researchers as 'the glass cliff', in which women are more often called into corporate leadership roles in times of crisis, and are therefore subject to more criticism if companies don't perform well."
\end{abstract}

\begin{abstract}
"While Uber's decision to approach women for the role was seen as an attempt to claw back some respect after high-profile accusations of a toxic macho culture in its offices, it plays into a pattern seen across US businesses, experts say."
\end{abstract}

"Women also get blamed harder than men if they have trouble, analysts claim."

As can be seen from these examples, the writers add citation which reinforces the previous discussion that women are characterized as glass cliff and subject to more criticism. According to Dor and Ferree (in Baden \& Tenenboim-Weinblatt, 2016), the use of sources in the news is to elucidate in what (additional) ways the presented views matter to the readers. News is also constructing the input to connect the statements given by other newsworthy sources and enriching with specific claims to authority and relevance (Esser \& Strömbäck in Baden \& TenenboimWeinblatt, 2016). Therefore, the writers add sources from studies and experts to support their statements. Based on the 
analyze at the level of discourse, it can be concluded that the way the writers use sources in the news is based on the phenomenon that happens in the workplace. They describe women by their role in the company.

The examples reinforce the previous discussion that the glass cliff phenomenon and the discrimination of women have been prevalent in the workplace industry. The existing stereotypes of women and their abilities influence how women are represented in the news texts. Women at the level of executives are indeed discriminated in the industry, and they are still struggling for gender equality.

\section{CONCLUSIONS}

Consequently, the findings in the present research are consistent with the previous researches on women in the news, that women remain underrepresented in news media. Beside underrepresented, women are also represented based on the stereotypes that exist in the United States culture. The first representation of women's CEO in this research is as an object in the stories and representing them as the solution of Uber's sexism issues. As the background of the story mentioned, Uber has sexual harassment scandals; therefore, it is needed a female CEO to recreate a good image in the company. Furthermore, the news portrays women as a minority which only considered as CEO when the company facing a crisis, or as known as 'the glass cliff'. Above all, they also have a high chance to be judged harsher than if they fail at their job to recreate a good image in the company.

There are several reasons why women's CEO are represented that way. As has been discussed, gender stereotypes are still existing in the United States. The 'glass cliff position' makes women in male-dominated industries get stereotypes which block women's way of stepping into leadership roles. Besides that, the background story of Uber, which has terrible images because of the sexual harassment and discrimination problems in the company also become the reason why women are represented as 'glass cliff position'. Moreover, Uber is a male-dominated industry which leads to a toxic work culture which makes the female workers get unfair treatment and discrimination. More importantly, the researches cited by the writers also confirm that the glass cliff phenomenon and the discrimination of women have been prevalent in the workplace industry.

Despite the coverage of the absence of women from the CEO candidates, most of the writers position women as the object of telling. The writers also use different terms and metaphor in describing women and men. Moreover, the writers as the narrators of the story tend to describe women as the object by giving references from experts and studies on the women reputation in the job and leadership roles. These show how the writers frame women in the news. The writers perceive Uber's idea to approach women as the new CEO as a way to restore the bad credibility that's why there is none of female CEO want to accept the offer. However, the writers represent women by the reasons why women are more likely to be in the glass cliff position and only added sources which support their narrative.

The implication of future research is that further studies are badly needed in terms of analyzing news from a feminist communication style. According to many researchers, women and men differ in the way they communicate. Therefore, communication styles can be analyzed from the perspective of feminist.

\section{REFERENCES}

Ali, R., \& Batool, S. (2015). Stereotypical identities: Discourse analysis of media images of women in Pakistan. Multidisclipinary Journal of Gender Studies, 4(1), 690-717. https://doi.org/10.4471/ generos.2015.54.

Aznar, M. P. M., Rodríguez-Wangüemert, C., \& Espinosa Morales, I. E. (2017). Portrayal of women and men in Spanish press. Revista Latina de Comunicación Social, 72, 765-782. https://doi.org/10.4185/RLCS, 72-2017-1191en.

Baden, C., \& Tenenboim-Weinblatt, K. (2016). Viewpoint, testimony, action. Journalism Studies, 19(1), 143161. https://doi.org/10.1177/1464884907078659.

Bruckmuller, S., Ryan, M. K., Rink, F., \& Haslam, S. A. (2014). Beyond the glass ceiling: The glass cliff and its lessons for organizational policy. Social Issues and Policy Review, 8(1), 202-232. https://doi. org/10.1111/sipr.12006.

Darta, D. M. S., \& Kristina, D. (2018). The representation of women characters in the movie "The Breadwinner". International Journal of Humanity Studies, 2(1), 4250. https://doi.org/10.24071/ijhs.2018.020105.

Darweesh, A. D., \& Abdullah, N. M. (2016). A critical discourse analysis of Donald Trump's sexist ideology. Journal of Education and Practice, 7(30), 87-95.

Geertsema-Sligh, M.(2019). Gender issues in news coverage. In The International Encyclopedia of Journalism Studies (pp 1-8). New Jersey: John Wiley \& Sons, Inc. $\quad$ https://doi.org/10.1002/9781118841570. iejs0162.

Jia, S., Landdall-Welfare, T., Sudhahar, S., \& Carter, C. (2016). Women are seen more than heard in online newspapers. PLoS ONE, 11(2), 1-11. https://doi.org/ doi:10.1371/journal.pone.0148434.

Kristina, D. (2019). Analisis wacana kritis: Pengantar praktis. Jakarta: Akademi Sekolah Darurat Kartini.

Len-Rios, M. E., Rodgers, S., Thorson, E., \& Yoon, D. (2005). Representation of women in news and photos: Comparing content to perceptions. Journal of Commmunication, 55(1), 152-168. https://doi. org/10.1111/j.1460-2466.2005.tb02664.x.

Mills, S. (1988). Feminist stylistics. London: Routledge.

Mills, S. (1998). Post-feminist text analysis. Language and Literature 7(3), 235-252. https://doi. org/10.1177/096394709800700304.

Newman, N., Fletcher, R., Kalogeropoulos, A., Levy, D. A. L., \& Nielsen, R. K. (2017). Reuters institute digital news report 2017. Oxford: Reuters Institute for the Study of Journalism.

Ramanathan, R. (2015). Application of critical discourse analysis in media discourse studies. The Southeast Asian Journal of English Language Studies, 21(2), 57-68.

Ryan, K. (2013). The media's war on women: Gendered coverage of female candidates. Xavier Journal of Politics, 4(1), 13-25.

Shor, E., Van de Rijt, A., Miltsov, A., Vivek, K., \& Skiena, S. (2015). A paper ceiling: Explaining the persistent 
underrepresentation of women in printed news. American Sociological Review, 80(5), 960-984. https://doi.org/10.1177/0003122415596999.

Suryaningrum, S., Suwandi, S., \& Waluyo, H. J. (2019). The discrimination against women reflected in novels "Entrok", "Maryam", and "Pasung Jiwa" by Okky Madasari. Lingua Cultura, 13(2), 137-143. https:// doi.org/10.21512/lc.v13i2.5704.

Van Dijk, T. A. (2015). Critical discourse analysis. In D. Tannen, H. E. Hamilton, \& D. Schiffrin (Eds.), The Handbook of Critical Discourse Analysis (Second edition, pp. 466-485). New Jersey: John Wiley \& Sons, Inc. https://doi.org/10.1002/9781118584194. $\operatorname{ch} 22$. 